\title{
Thioredoxin Modulates Protein Arginine Deiminase 4 (PAD4)-Catalyzed Citrullination
}

\author{
Mitesh Nagar ${ }^{1,2}$, Ronak Tilvawala ${ }^{1,2}$ and Paul R. Thompson ${ }^{1,2 *}$ \\ ${ }^{1}$ Department of Biochemistry and Molecular Pharmacology, University of Massachusetts Medical School, Worcester, MA, \\ United States, ${ }^{2}$ Program in Chemical Biology, University of Massachusetts Medical School, Worcester, MA, United States
}

Protein citrullination is a post-translational modification catalyzed by the protein arginine deiminases (PADs). This modification plays a crucial role in the pathophysiology of numerous autoimmune disorders including RA. Recently, there has been a growing interest in investigating physiological regulators of PAD activity to understand the primary cause of the associated disorders. Apart from calcium, it is well-documented that a reducing environment activates the PADs. Although the concentration of thioredoxin ( $\mathrm{hTRX}$ ), an oxidoreductase that maintains the cellular reducing environment, is elevated in RA patients, its contribution toward RA progression or PAD activity has not been explored. Herein, we demonstrate that hTRX activates PAD4. Kinetic characterization

OPEN ACCESS

Edited by:

Uday Kishore,

Brunel University London,

United Kingdom

Reviewed by:

Huw Lewis,

GlaxoSmithKline, United Kingdom

Gunnar Houen,

State Serum Institute (SSI), Denmark

*Correspondence:

Paul R. Thompson

paul.thompson@umassmed.edu

Specialty section:

This article was submitted to

Molecular Innate Immunity,

a section of the journal

Frontiers in Immunology

Received: 09 July 2018

Accepted: 28 January 2019

Published: 19 February 2019

Citation:

Nagar $M$, Tilvawala $R$ and Thompson PR (2019) Thioredoxin Modulates Protein Arginine Deiminase 4 (PAD4)-Catalyzed Citrullination.

Front. Immunol. 10:244.

doi: 10.3389/fimmu.2019.00244 of PAD4 using hTRX as the reducing agent yielded parameters that are comparable to those obtained with a routinely used non-physiological reducing agent, e.g., DTT, suggesting the importance of $\mathrm{hTRX}$ in PAD regulation under physiological conditions. Furthermore, we show that various hTRX mutants, including redox inactive hTRX variants, are capable of activating PAD4. This indicates a mechanism that does not require oxidoreductase activity. Indeed, we observed non-covalent interactions between PAD4 and $\mathrm{hTRX}$ variants, and propose that these redox-independent interactions are sufficient for hTRX-mediated PAD4 activation.

Keywords: thioredoxin, PAD4, citrullination, rheumatoid arthritis, autoantibodies, NETosis

\section{INTRODUCTION}

Protein citrullination is a post-translational modification that converts a positively charged arginine residue into a neutral citrulline $(1,2)$. Modifications of such charged residues can alter various protein properties, including protein-protein interactions and protein-DNA interactions, with consequent effects on various physiological processes (2-4). For example, histone hypercitrullination leads to chromatin decondensation and ultimately the release of neutrophil extracellular traps (NETs), which are involved in the innate immune response against various pathogens as well as in the pathogenesis of autoimmune and inflammatory disorders (5-7). In fact, protein citrullination has been extensively studied in the context of rheumatoid arthritis (RA) due to the presence of autoantibodies against citrullinated proteins (ACPA) in over 70\% of RA patients $(3,8-10)$. ACPA are highly specific and widely used for the diagnosis of RA $(11,12)$. Apart from autoimmune diseases, like RA, lupus, multiple sclerosis, and ulcerative colitis (13-15), aberrant citrullination has also been shown to play a role in the pathology of various neurodegenerative diseases, diabetes, and cancer (16-19). Therefore, the group of enzymes that catalyze protein 
citrullination, the protein arginine deiminases (PADs), are attractive therapeutic targets $(13,14,20-24)$. For this reason, most PAD-focused studies investigate their pathophysiological functions rather than their physiological roles under normal circumstances. Importantly, it is still unclear how PAD activity is regulated and how aberrant regulation leads to various pathological conditions.

There are five human PAD isozymes (PAD1-4 and PAD6). These isozymes are localized in specific tissues to carry out distinct physiological functions. For example, PAD1 and PAD3 are expressed in the skin and hair follicles and regulate the cellular architecture. PAD2 and PAD4 play roles in apoptosis, gene regulation, and NET-formation (2, 6, 25-27). Amongst the PAD family, PAD2 and PAD4 are of particular interest because these isozymes are expressed mainly in immune cells and have been implicated in a variety of autoimmune and inflammatory disorders $(3,13-15,28,29)$. All the active PADs (PAD1-4) share similar catalytic mechanisms and their activity is regulated by calcium through important conformational changes that facilitate PAD-catalysis (30-32). In addition to calcium, bicarbonate and GSH regulate PAD2 and PAD4 activity under physiological conditions $(33,34)$. Since redox balance is a necessary requirement for PAD activity, thioredoxin (hTRX), a $12 \mathrm{kDa}$ protein that regulates redox homoeostasis in all tissues of the human body (35-37), is another candidate that could impact PAD-catalyzed citrullination. In fact, numerous studies have shown elevated levels of hTRX in serum and synovial samples from RA patients (38-42) suggesting hTRX activity might contribute to RA progression; however its role in PAD activation has yet been established.

Herein, we report the impact of hTRX on PAD activity using the synthetic substrate mimic $N_{\alpha}$-benzoyl-L-arginine ethyl ester (BAEE) and verified our results with the physiological substrate histone H3. Moreover, we used a variety of hTRX mutants to show that hTRX activates PAD4 in a redox-independent manner.

\section{MATERIALS AND METHODS}

\section{Plasmids}

His-tagged human wild-type hTRX and C35S, C32/35S, C62S, C69S, and C73S-hTRX variants were kind gifts from Dr. Weerapana (Boston College, MA). The C32/35/69S and C62/69ShTRX mutants were created in house.

\section{Preparation of Proteins Thioredoxins}

Wild-type hTRX and its mutants were purified in the absence of any reducing agents as described previously (43). All variants were fully reduced with DTT $(10 \mathrm{mM})$ for $10 \mathrm{~min}$ at $37^{\circ} \mathrm{C}(44)$ and the excess DTT was removed by exhaustive buffer exchange using amicon centrifugal filters $(3 \mathrm{kDa})$.

Abbreviations: hTRX, human thioredoxin; GSNO, S-nitrosoglutathione; RA, rheumatoid arthritis; PAD, protein arginine deiminase; ACPA, anti-citrullinated protein antibodies; NET, neutrophil extracellular trap; BAEE, $N_{\alpha}$-benzoyl arginine ethyl ester; PBS, phosphate buffered saline; BSA, bovine serum albumin.

\section{PAD4}

Purification of human PAD4 was carried out as described previously (45) but without reducing agent. $S$-nitrosoglutathione (GSNO) and $\mathrm{H}_{2} \mathrm{O}_{2}$-modified PAD4 were prepared by incubating PAD4 with GSNO $(200 \mu \mathrm{M})$ or $\mathrm{H}_{2} \mathrm{O}_{2}(100 \mu \mathrm{M})$ for $10 \mathrm{~min}$ at $37^{\circ} \mathrm{C}$. Excess reagents were removed by exhaustive buffer exchange using amicon centrifugal filters $(10 \mathrm{kDa})$.

\section{PAD4 Activity Assay Using BAEE as Substrate}

PAD4 activation was determined using a previously described discontinuous colorimetric assay (45). Briefly, reaction buffer (Tris- $\mathrm{HCl}, 100 \mathrm{mM} ; \mathrm{pH}$ 7.6; $\mathrm{NaCl}, 50 \mathrm{mM}$ ) containing $\mathrm{CaCl}_{2}$ $(10 \mathrm{mM}), \operatorname{BAEE}(10 \mathrm{mM})$, and hTRX $(0-10 \mu \mathrm{M})$ was preincubated at $37^{\circ} \mathrm{C}$ for $10 \mathrm{~min}$ followed by the addition of PAD4 (final concentration of $0.2 \mu \mathrm{M})$ to initiate the reaction $(60 \mu \mathrm{L}$ final volume). After $10 \mathrm{~min}$, reactions were quenched by adding $200 \mu \mathrm{L}$ of freshly prepared COLDER solution $\left[\mathrm{H}_{3} \mathrm{PO}_{4}, 2.25 \mathrm{M}\right.$; $\mathrm{H}_{2} \mathrm{SO}_{4}, 4.5 \mathrm{M}$; $\mathrm{NH}_{4} \mathrm{Fe}\left(\mathrm{SO}_{4}\right), 1.5 \mathrm{mM}$; diacetyl monoxime, $20 \mathrm{mM}$; and thiosemicarbazide, $1.5 \mathrm{mM}$ ] and incubated for $30 \mathrm{~min}$ at $95^{\circ} \mathrm{C}$ for color development. Sample absorbance was measured at $540 \mathrm{~nm}$ to determine the amount citrulline produced during the course of the reaction using a citrulline standard. Control activity of PAD4 was measured using a saturating concentration of DTT (2 mM) (45).

\section{Using Histone $\mathrm{H} 3$ as Substrate}

Previously purified Histone $\mathrm{H} 3(10 \mu \mathrm{M})$ (46) was treated with PAD4 $(0.2 \mu \mathrm{M})$ in reaction buffer containing thioredoxin $(0.0 .08$, $0.17,0.33,0.67,1.33$, and $2.67 \mu \mathrm{M}$ ) at $37^{\circ} \mathrm{C}$ (total volume $30 \mu \mathrm{L}$ ) for $10 \mathrm{~min}$ and then the reaction was quenched using $6 \mathrm{X}$ SDSPAGE loading dye followed by $10 \mathrm{~min}$ incubation at $95^{\circ} \mathrm{C}$ before running samples on SDS-PAGE. Separated proteins were then transferred to PVDF membrane (Bio-Rad) at $80 \mathrm{~V}$ for $50 \mathrm{~min}$. The membrane was then blocked with PBS containing Tween-20 $(0.1 \%, \mathrm{PBST})$ and BSA (5\%) for $1 \mathrm{~h}$ at room temperature before adding primary antibodies for PAD4 (rabbit, 1:1,000, Proteintech cat\# 7373-1-AP), histone H3 (mouse, 1:1,000, Abcam cat\# ab10799), and histone H3-Cit-2,8,17 (rabbit, 1:1,000, Abcam cat\# ab5103) and further incubated overnight at $4^{\circ} \mathrm{C}$. The next day, after washing with PBST $(3 \times)$, the membrane was incubated with secondary anti-rabbit IgG Licor conjugate antibody (1:5,000) for $1 \mathrm{~h}$ at room temperature. Finally, the membrane was imaged and quantified using LICOR Odyssey Imaging System.

\section{hTRX Activity Assay}

The hTRX-activity assay was performed as per the manufacturer's instructions (Cayman Chemical Co., cat\# 20039). Briefly, various hTRX variant samples $(10 \mu \mathrm{L}$ of $1.0 \mu \mathrm{M}$ solution) were added to a 96-well half area black plate followed by addition of assay buffer $(55 \mu \mathrm{L})$, human thioredoxin reductase $(10 \mu \mathrm{L}$ of $1.0 \mu \mathrm{M}$ solution), and NADPH (5 $\mu \mathrm{L}$, diluted according to kit instructions) to each sample well. The plate was then incubated at $37^{\circ} \mathrm{C}$ for $30 \mathrm{~min}$. After incubation, fluorescent substrate $(20 \mu \mathrm{L}$, diluted according to kit instructions) was added to each sample as quickly as possible. The plate was immediately placed in an Envision plate reader (Molecular Devices) and fluorescence was 
A

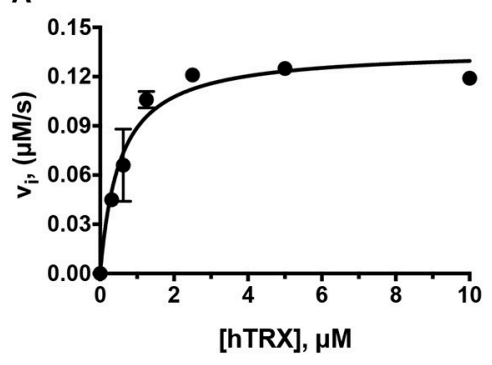

C

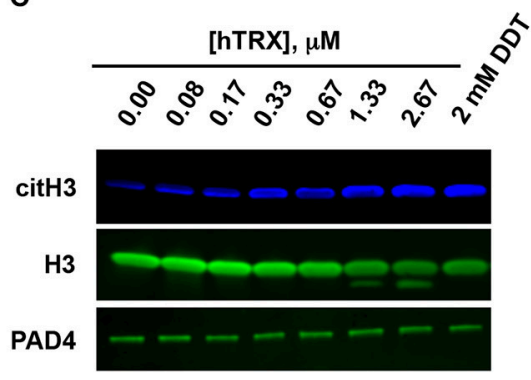

B

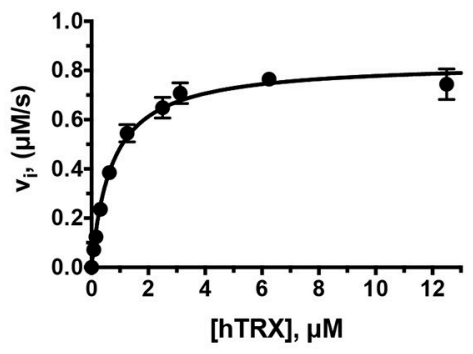

D

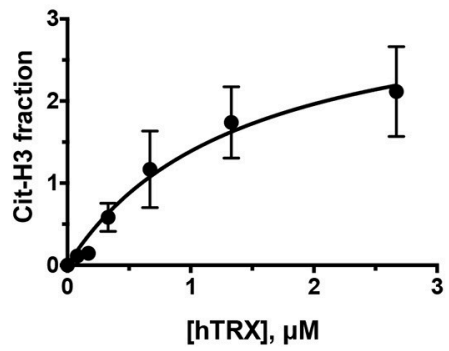

FIGURE 1 | Effect of hTRX on PAD4 activity. Rate of citrullination of BAEE by PAD4 in presence of various concentrations of untreated (A) and DTT-treated hTRX (B). Histone $\mathrm{H} 3$ citrullination by PAD4 in the presence of various hTRX concentrations (C). The quantification of the western blot, i.e., citH3/H3 ratio, with increasing concentration of hTRX (D)

monitored at $480 \mathrm{~nm}$ excitation and $520 \mathrm{~nm}$ emission for $15 \mathrm{~min}$. Reaction rates were plotted and compared.

\section{hTRX Interaction With PAD4}

\section{Size-Exclusion Chromatography}

PAD4 $(12 \mu \mathrm{M}$ ) and hTRX (or its variants, $80 \mu \mathrm{M}$ ) were incubated in size-exclusion buffer (SEC-buffer, Tris-Cl, $100 \mathrm{mM}$; $\mathrm{pH} 7.6$; $\mathrm{NaCl}, 50 \mathrm{mM}$, and $\mathrm{CaCl}_{2}, 10 \mathrm{mM}$ ) at $37^{\circ} \mathrm{C}$ for $10 \mathrm{~min}$ (final volume $100 \mu \mathrm{L}$ ). This mixture was diluted with $300 \mu \mathrm{L}$ of SECbuffer and loaded onto a size exclusion column (Superdex 200 10/300 GL, GE Healthcare) attached to an ÄKTA-FPLC. The proteins were separated with a flow rate of $0.5 \mathrm{~mL} / \mathrm{min}$. Peak fractions $(1 \mathrm{~mL})$ corresponding to the PAD4 dimer and PAD4 monomer were concentrated $10 \mathrm{X}$ and subjected to denaturing SDS-PAGE followed by blotting on PVDF membrane (see above). Primary antibodies against PAD4 (rabbit, 1:1,000, Proteintech cat\# 7373-1-AP) and thioredoxin (mouse, 1:1,000, Abcam cat\# ab16965) were used to evaluate the presence of hTRX in PAD4 peaks.

\section{Immunoprecipitation (IP)}

HL60 cells were grown in RPMI 1640 medium (w/Lglutamine and HEPES) supplemented with 10\% FBS and penicillin/streptomycin at a density of $3 \times 10^{5}$ cells $/ \mathrm{mL}$. Differentiation of HL60 cells to granulocytes was induced by $1.3 \%$ dimethyl sulfoxide (DMSO) and then the cells were allowed to grow for 4 days before harvesting. After washing the cell pellet with PBS $(3 \times)$, cells were lysed using lysis buffer (Tris-Cl, $25 \mathrm{mM}, \mathrm{pH}$ 7.4; $\mathrm{NaCl}, 50 \mathrm{mM} ; \mathrm{CaCl}_{2}, 2 \mathrm{mM}$ and $1 \% \mathrm{NP} 40$ ) containing protease inhibitor cocktail. Clarified cell lysates
(1.2 $\mathrm{mg}$ total protein) were incubated with anti-PAD4 $(4 \mu \mathrm{g}$, rabbit, Proteintech cat\# 7373-1-AP) or generic rabbit IgG (4 $\mu \mathrm{g}$ ) for overnight at $4{ }^{\circ} \mathrm{C}$ with gentle rotation. Protein $\mathrm{A} / \mathrm{G}$ plus-agarose beads (100 $\mu \mathrm{L}$ slurry, Santa Cruz Biotechnology) were added to the mixture and incubated for another $4 \mathrm{~h}$ at $4{ }^{\circ} \mathrm{C}$ to capture antibody-bound protein complexes. The beads were then washed $(3 \times)$ with wash buffer [Tris-Cl, $25 \mathrm{mM}(\mathrm{pH}$ 7.4); $\mathrm{NaCl}, 50 \mathrm{mM}, \mathrm{CaCl}_{2}, 2 \mathrm{mM}$; and $\left.0.2 \% \mathrm{NP}-40\right]$, and the protein complexes were eluted using $2 \times$ SDS sample buffer. Eluted proteins were immunoblotted as mentioned above using primary antibodies against PAD4 (mouse 1:1,000, Abcam cat\# 128086) and thioredoxin (mouse, 1:1,000, Abcam cat\# ab16965). HRP-conjugated goat anti-mouse antibody (1:10,000, Invitrogen cat \# 31432) was used to evaluate the presence of hTRX and PAD4 in the elution fraction by detecting chemiluminescence using an ECL kit (GE Healthcare Amersham).

\section{RESULTS}

\section{Effect of hTRX on PAD4 Activity}

To investigate whether hTRX can influence PAD4 activity, we used BAEE (Figures 1A,B) and histone $\mathrm{H} 3$ as substrates (Figures 1C,D). Purified hTRX activated PAD4 in a concentration-dependent manner and displayed saturation kinetics (Figures 1A,B). Although DTT-treated hTRX showed better activation (Figure 1B), maximal PAD4 activity was still observed at $5 \mu \mathrm{M}$ of hTRX (Figures 1A,B). Therefore, all other kinetic assays were performed using this saturating concentration of reduced-hTRX. 

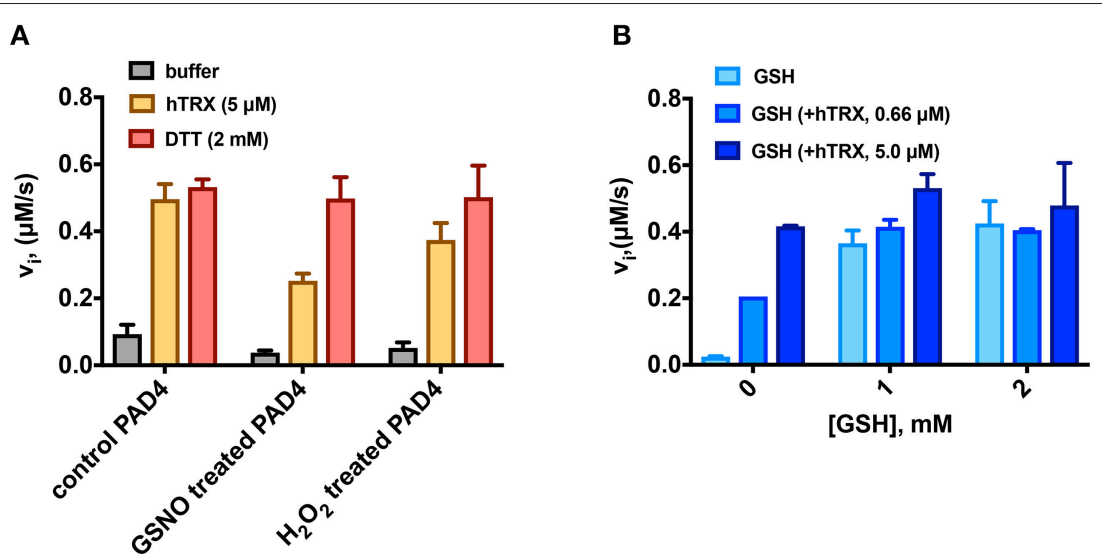

FIGURE 2 | Activation of PAD4 in the presence of various reducing agents. (A) Reactivation of GSNO- and $\mathrm{H}_{2} \mathrm{O}_{2}$-treated PAD4 by reducing agents. Rate of citrullination of BAEE by PAD4 [treated with GSNO $(200 \mu \mathrm{M})$ or $\mathrm{H}_{2} \mathrm{O}_{2}(100 \mu \mathrm{M})$ for 10 min at $37^{\circ} \mathrm{C}$ ] measured in presence of hTRX or DTT. (B) Combined effect of physiological reducing agents on PAD4 activation. PAD4 activity was measured in the presence of various concentrations of GSH containing sub-saturating (0.66 $\mu \mathrm{M})$ and saturating concentrations of $\operatorname{hTRX}(5 \mu \mathrm{M})$.
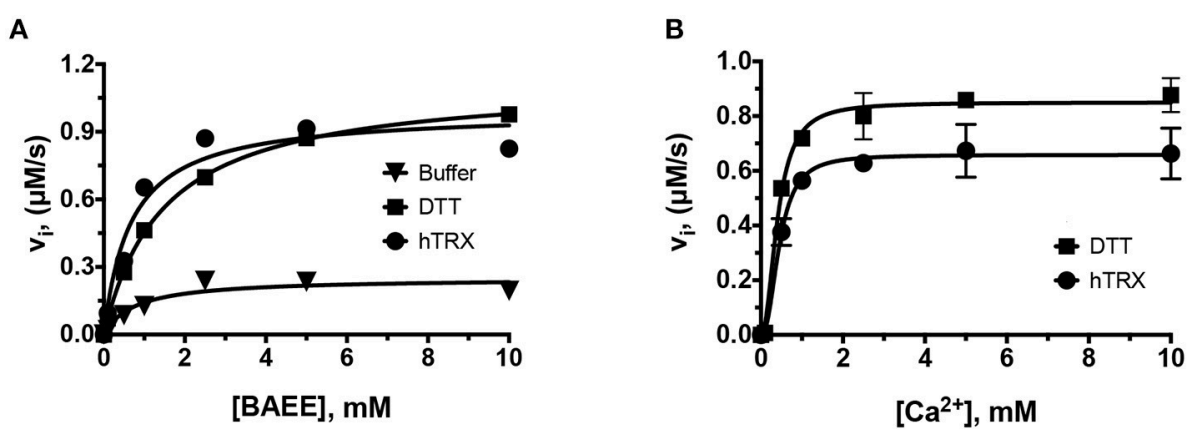

C

\begin{tabular}{lcccc}
\hline $\begin{array}{c}\text { reducing } \\
\text { agent }\end{array}$ & $\boldsymbol{k}_{\text {cat }}\left(\mathbf{s}^{-1}\right)$ & $\boldsymbol{K}_{\mathrm{m}}(\mathbf{m M})$ & $\begin{array}{c}\boldsymbol{k}_{\text {cat }} / \boldsymbol{K}_{\mathrm{m}} \\
\left(\mathbf{M}^{-1} \mathbf{s}^{-1}\right) \times 10^{3}\end{array}$ & $\boldsymbol{K}_{0.5}{ }^{\mathrm{Ca} 2+}(\mathbf{m M})$ \\
\hline Buffer & $1.25 \pm 0.15$ & $0.76 \pm 0.35$ & $1.6 \pm 0.1$ & - \\
DTT & $5.62 \pm 0.04$ & $1.48 \pm 0.01$ & $3.8 \pm 0.1$ & $0.41 \pm 0.03$ \\
hTRX & $4.95 \pm 0.39$ & $0.66 \pm 0.21$ & $7.1 \pm 2.1$ & $0.43 \pm 0.02$ \\
\hline
\end{tabular}

FIGURE 3 | Kinetic characterization of PAD4. (A) Michaelis-Menten plots of PAD4 with various BAEE concentrations in presence of hTRX (5 $\mu$ M), DTT (2 mM), and buffer as control. Refer to Figure S1 for PAD1, PAD2, and PAD3 data. (B) Calcium-dependence of PAD4 with hTRX and DTT as reducing agents. (C) Kinetic parameters deduced from (A,B).

\section{Activation of PAD4 With Various Reducing Agents}

The role of the oxidoreductase activity of hTRX was further evaluated by re-activating PAD4 after mild treatment with thioloxidizing $\left(\mathrm{H}_{2} \mathrm{O}_{2}\right)$ and -nitrosylating (GSNO) agents (Figure 2A). Under both situations, hTRX revived PAD4 activity; but unlike control, only 50\% (GSNO-treated PAD4) and 75\% $\left(\mathrm{H}_{2} \mathrm{O}_{2}\right.$-treated $\mathrm{PAD} 4)$ of the activity revived by the in vitro reducing agent DTT (Figure 2A). Since GSH is a known co-activator of PADs, the combined effect of hTRX and GSH on PAD4 activity was also examined. PAD4 activity was measured in the presence of various concentrations of GSH containing sub-saturating (near
$K_{\mathrm{d}}$ value) and saturating concentrations of hTRX (as determined in the previous section). As expected both hTRX $(5 \mu \mathrm{M})$ and GSH (2 mM) individually showed activation of PAD4, but when used in combination there was only slight increase in maximum activity (Figure 2B).

\section{Kinetic Characterization of PAD4 Using hTRX as Reducing Agent}

Next, the kinetic parameters of PAD4 for BAEE were determined in the presence of hTRX $\left(k_{\text {cat }}^{\text {hTRX }}=5.0 \pm 0.4 \mathrm{~s}^{-1} ; K_{\mathrm{m}}^{\mathrm{hTRX}}=\right.$ $\left.0.7 \pm 0.2 \mathrm{mM} ; K_{0.5}^{\mathrm{Ca} 2+}=0.43 \pm 0.02 \mathrm{mM}\right)$ and compared to the kinetic parameters obtained in presence of DTT $\left(k_{\text {cat }}^{\mathrm{DTT}}=5.62 \pm\right.$ 
A

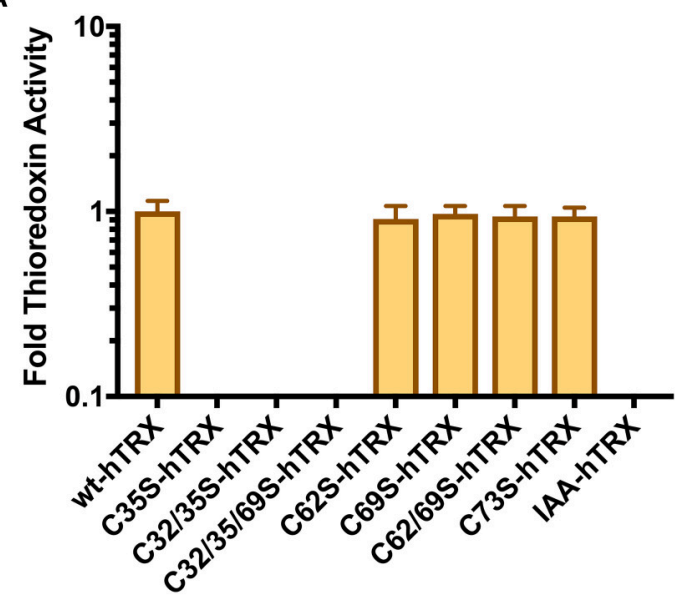

B

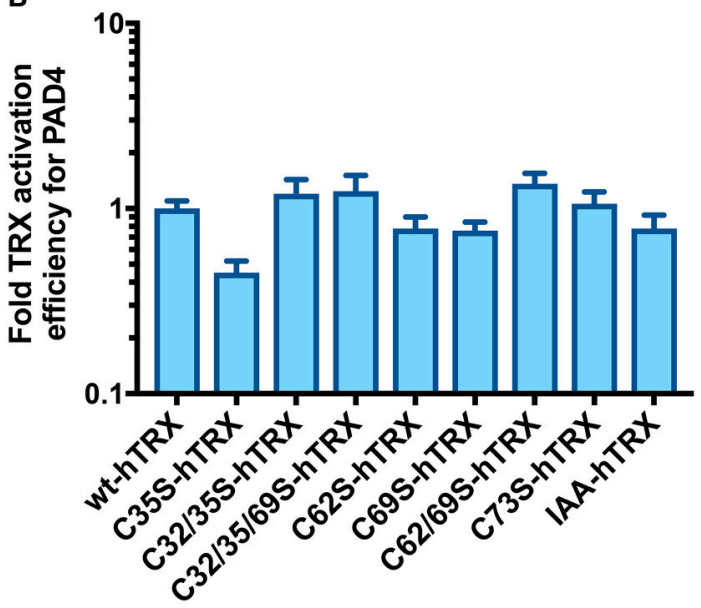

FIGURE 4 | Activation of PAD4 in presence of hTRX variants. (A) Effect of hTRX mutations and IAA-treatment on its oxidoreductase activity. The hTRX activity was measured using a kit from Cayman Chemical Co. (cat\# 20039). (B) Effect of various hTRX mutants on the catalytic efficiency of PAD4. Refer to Table $\mathbf{1}$ for the raw data. Fold change in thioredoxin activity or thioredoxin activation efficiency for PAD4 for the hTRX mutants are calculated with respect to wild-type hTRX.

$\left.0.04 \mathrm{~s}^{-1} ; K_{\mathrm{m}}^{\mathrm{DTT}}=1.48 \pm 0.01 \mathrm{mM} ; K_{0.5}^{\mathrm{Ca} 2+}=0.41 \pm 0.03 \mathrm{mM}\right)$ (Figures $3 \mathbf{A}-\mathrm{C}$ ). In both cases, all kinetic parameters including the $\mathrm{Ca}^{2+}$-dependence, were quite comparable (i.e., within one- to two-fold), suggesting hTRX could be the major PAD4 reducing agent under physiological conditions. In addition to PAD4, we also observed higher PAD1, PAD2, and PAD3 activity with buffer containing hTRX compared to buffer without any reducing agent, suggesting that the reducing activity of hTRX can activate all PAD isozymes (Figure S1).

\section{Impact of Redox-Activity of hTRX on PAD4 Activation}

To determine how hTRX activates PAD4, we first created various thioredoxin mutants and confirmed their oxidoreductase activity using a commercial assay kit. As expected, none of the hTRX
TABLE 1 | Activation of PAD4 by various hTRX variants.

\begin{tabular}{lccc}
\hline hTRX & $\boldsymbol{V}_{\text {max }}(\boldsymbol{\mu} \mathbf{M} / \mathbf{s})$ & $\boldsymbol{K}_{\mathbf{d}(\mathbf{a p p})}(\boldsymbol{\mu} \mathbf{M})$ & $\left(\boldsymbol{V}_{\max } / \mathrm{E}_{\mathbf{T}}\right) \boldsymbol{K}_{\mathbf{d}(\mathbf{a p p})}$ \\
& & & $\left(\mathbf{M}^{-\mathbf{1}} \mathbf{s}^{-\mathbf{1}}\right) \times \mathbf{1 0}^{\mathbf{6}}$ \\
\hline WT & $0.83 \pm 0.01$ & $0.72 \pm 0.05$ & $5.7 \pm 0.4$ \\
C35S & $0.62 \pm 0.02$ & $1.17 \pm 0.14$ & $2.6 \pm 0.4$ \\
C32/35S & $0.61 \pm 0.02$ & $0.44 \pm 0.08$ & $7.0 \pm 1.3$ \\
C32/35/69S & $0.43 \pm 0.02$ & $0.30 \pm 0.06$ & $7.2 \pm 1.5$ \\
C62S & $1.03 \pm 0.04$ & $1.14 \pm 0.14$ & $4.5 \pm 0.6$ \\
C69S & $1.05 \pm 0.05$ & $1.38 \pm 0.19$ & $3.8 \pm 0.4$ \\
C62/69S & $0.96 \pm 0.03$ & $0.61 \pm 0.07$ & $7.9 \pm 1.0$ \\
C73S & $0.96 \pm 0.04$ & $0.78 \pm 0.11$ & $6.2 \pm 0.9$ \\
IAA-hTRX & $0.56 \pm 0.02$ & $0.62 \pm 0.10$ & $4.5 \pm 0.7$ \\
\hline
\end{tabular}

$K_{d(a p p)}$, apparent binding affinity of PAD4 for hTRX variant.

$\left.N_{\max } / E_{T}\right) / K_{d(\text { app })}$, pseudo activation-efficiency of $h T R X$ variants.

active-site mutants, i.e., C35S, C32/35S, and C32/35/69S, were redox active (Figure 4A). Interestingly, these mutants were equally potent in activating PAD4 compared to wild typehTRX (Figure 4B, Table 1). In addition, other redox-active TRX cysteine mutants (C62S, C69S, C62/69S, and C73S) behaved like wt hTRX and showed PAD4 activation suggesting that no individual cysteine residue is necessary for PAD4 activation (Table 1). To test this hypothesis, we created a thiol-free variant of TRX by chemically modifying all cysteine residues with iodoacetamide. Indeed, IAA-treated hTRX showed no redox activity, but it was found to be as efficient as that of other redox active hTRX variants in enhancing the rate of PAD4-catalyzed citrullination (Figures 4A,B).

\section{hTRX Interaction With PAD4}

We then used size-exclusion chromatography and western blotting to investigate whether hTRX physically interacts with PAD4 (Figures 5A,B). The reaction mixture containing hTRX or the C32/35/69S-hTRX mutant and PAD4 yielded 3 major peaks after passing through the size-exclusion column. The first and second peaks represent dimeric and monomeric PAD4 respectively, and the last peak corresponds to hTRX (Figures 5A,B). Both PAD4 peaks were electro-transferred to a PVDF membrane and tested for the presence of hTRX using an anti-hTRX antibody. Samples from both redox-active hTRX and redox-inactive C32/35/69S-hTRX showed the presence of a corresponding hTRX band in the PAD4-containing lanes (Figures 5A,B), suggesting that these two proteins do interact in solution and that this interaction is not mediated though thiol-exchange.

Next, we determined whether hTRX interacts with PAD4 in vivo using a co-IP assay. IP experiments were performed using lysate of DMSO-differentiated HL60 cells that express higher levels of PAD4 (47) and anti-PAD4 (rabbit) antibody (Figure 5C). The presence of PAD4 and hTRX was evaluated in the input (lysate), unbound fractions (supernatant), and elution fractions (collected from the beads) using anti-PAD4 (mouse) and antihTRX (mouse) antibodies. The eluate from anti-PAD4 IP shows 

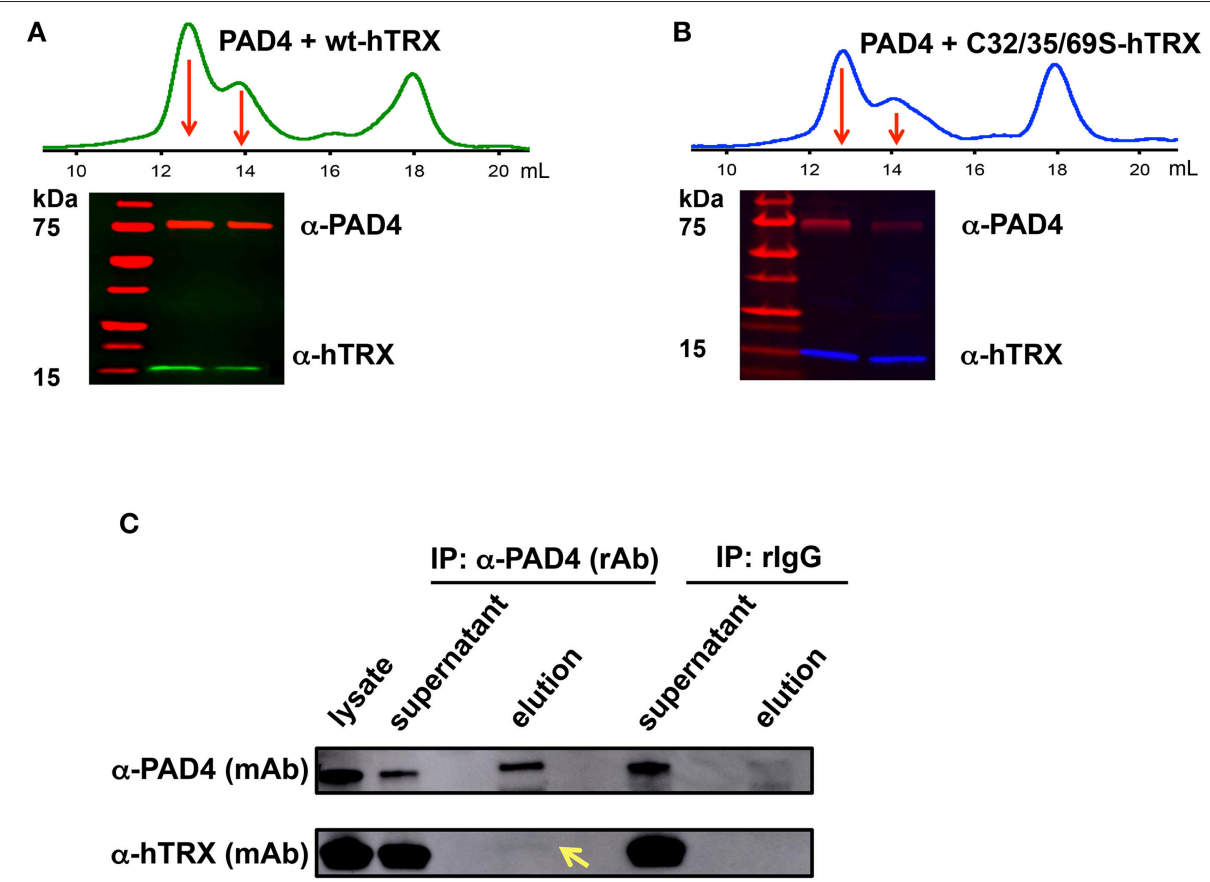

FIGURE 5 | Interaction between PAD4 and hTRX. Size-exclusion chromatogram shows the elution profile of hTRX-PAD4 (A, green) and C32/35/69S-hTRX-PAD4 (B, blue) reaction mixture. The first and the second peak (marked with arrows) corresponding to dimeric and monomeric PAD4, respectively, were subjected to denaturing SDS-PAGE and the subsequent western blot of the PAD4 peak fractions shows the presence of the corresponding hTRX variant. Co-immunoprecipitation of hTRX with PAD4 (C). Lysate from DMSO-differentiated HL60 cells was immunoprecipitated with anti-PAD4 (rAb) followed by western blot with anti-hTRX (mAb) and anti-PAD4 (mAb).

the presence of hTRX, confirming its interaction with PAD4 under cellular conditions (Figure 5C).

\section{DISCUSSION}

In recent decades, $\mathrm{PAD}$-catalyzed citrullination has come into focus due to its role in various autoimmune diseases including RA. Although the precise cause of RA is unknown, it is commonly accepted that various environmental factors (e.g., smoking) trigger PAD activity to generate citrullinated proteins against which genetically susceptible individuals produce ACPAs (48-50). Since inflammation and oxidative stress are closely related pathophysiological processes, it has been proposed that oxidative stress is also correlated with RA pathogenesis (51, 52). In fact, several studies show that subjects with RA have high oxidative stress compared to healthy individuals (40, 53, 54). Mammalian cells have two major anti-oxidative defense mechanisms: reduced glutathione (GSH) and thioredoxin (hTRX). Although GSH is the major redox regulator, this system is impaired during oxidative stress and therefore RA patients show decreased ( $<50 \%$ of healthy controls) levels of GSH (5558). Despite lower GSH levels, Damgaard et al. showed that GSH is a major physiological co-regulator of PAD activity (34). By contrast, oxidative stress induces hTRX production during infection and inflammation, and acts as a chemoattractant for immune cells such as neutrophils, monocytes and T-cells $(59,60)$. Consequently, hTRX levels are elevated in serum, synovial fluid, and synovial tissues of RA patients (38-42). Here, we provide a potential link between high TRX levels and enhanced protein citrullination during RA.

Our data show that hTRX promotes PAD-catalyzed citrullination in a concentration-dependent manner (Figures 1A-D). Although hTRX is not a PAD substrate, it exhibits Michaelis-Menten-type kinetics indicating complex formation between these two proteins through stabilizing interactions $(61,62)$. Therefore, the TRX concentration that produces half-maximum PAD activation can be used as an estimate for binding affinity of hTRX for PAD (similar to the observed $K_{\mathrm{m}}$ for a substrate) (Table 1). Enhanced activation of PAD4 by DTT-treated hTRX (Figures 1A,B), and reactivation of GSNO and $\mathrm{H}_{2} \mathrm{O}_{2}$-treated PAD4 by hTRX is in accord with the fact that a reducing environment is an important requirement for PAD activity (Figure 2A) (34). In fact, saturating concentrations of reduced hTRX showed similar effects on PAD catalysis as that of DTT (Figures 2A, 3). Interestingly, the optimal hTRX concentration to activate PAD4 is 400 -fold less than that of GSH (Figure 2B), but unlike GSH (34), hTRX does not impact the $\mathrm{Ca}^{2+}$-dependence of PAD4. Under physiological conditions, PAD4 activity is likely regulated by the balance of these two redox regulators and corresponding $\mathrm{Ca}^{2+}$-levels.

TRX contains two redox-active sites (Cys 32 and Cys 35) and (Cys 62 and Cys 69). The former pair catalyzes most redox activity, whereas the latter redox active dithiol/disulfide pair (Cys 62 and Cys 69) is utilized under oxidizing conditions 


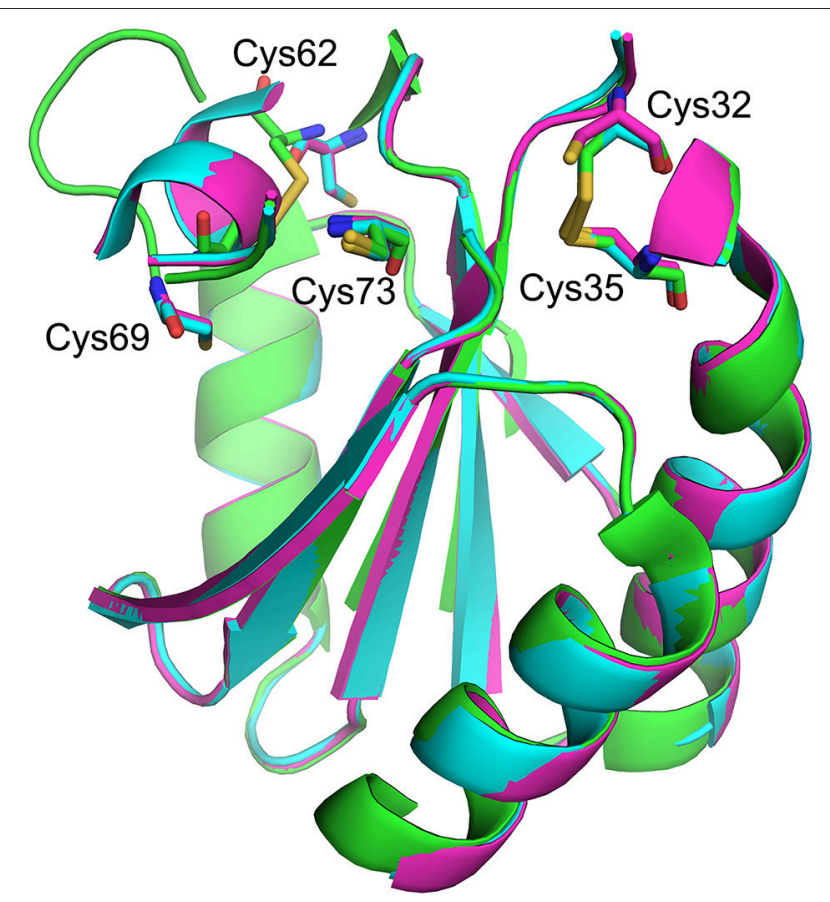

FIGURE 6 | Structural overlay showing redox-active sites of hTRX in various oxidation states. Fully reduced (magenta, [PDB: 1ERT]), partially oxidized (blue, [PDB: 1ERV]), and fully oxidized (green, [PDB: 5DQY]).

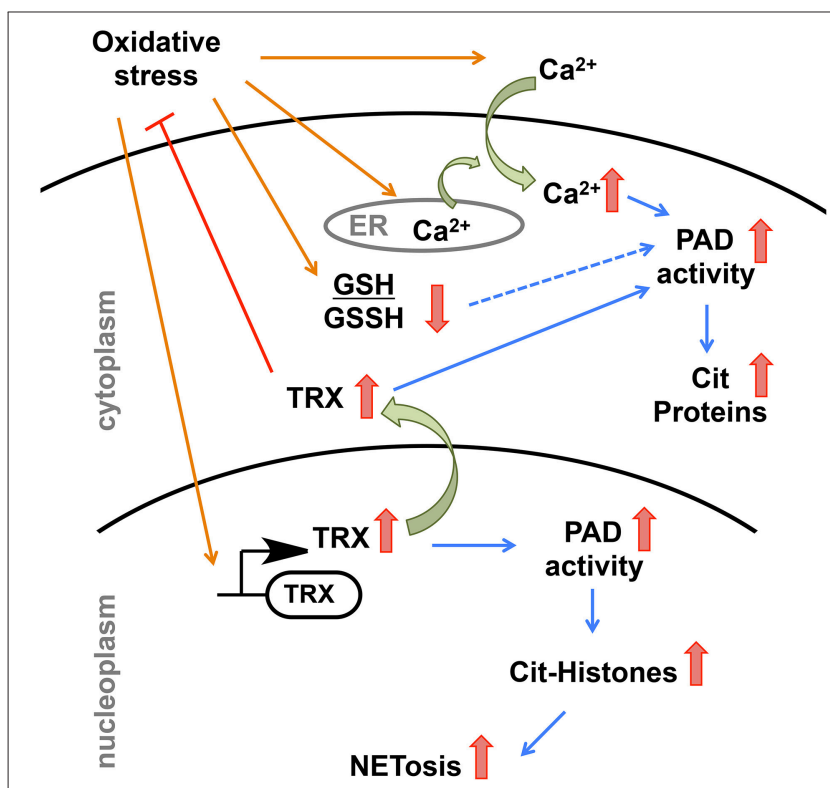

FIGURE 7 | Model depicting possible regulation of PAD4 activity upon environmental stimuli that induces oxidative stress.

(Figure 6) (63). Therefore, converting two active-site cysteines (Cys 32 and Cys 35) to serines yields hTRX variants devoid of classical redox activity, while changing Cys 62 and Cys 69 to serines has no impact on redox activity (Figure 5A). Surprisingly, redox-inactive hTRX variants, i.e., C35S, C32/35S, and $\mathrm{C} 32 / 35 / 69 \mathrm{~S}$ activated PAD4 to catalyze citrullination suggesting that the redox activity of TRX is not essential for PAD4 activation (Figures 4A,B). To our knowledge there are only few prior studies featuring such TRX behavior $(62,64,65)$. Liu et al. showed that TRX promotes ASK1 ubiquitination in a redox independent manner and that the association of TRX and ASK1 requires neither of the active site cysteines (Cys 32 or Cys 35) (64). Similarly, Huber et al. showed that active site cysteines are not required for TRX-dependent stimulation of DNA polymerase activity in E. coli but substitution or alkylation of these residues reduced the binding affinity by 60 -fold indicating role for a TRX active site in protein-protein interactions (65). On the contrary, our data show minimal effects (one- to two-fold) on binding of hTRX to PAD4 upon substituting redox-active cysteines with serines (Table 1) suggesting that the activityenhancing interactions may occur at residues other than redoxactive cysteines. In fact, similar observations are reported for the hTRX-dependent activation of chloroplast NADP malate dehydrogenase and fructose-bisphosphatase where Cys32/35S substitution had no impact on its interaction or activation profile compared to wild type TRX. Although unusual, it is possible that electrostatic interactions between TRX and the target protein leads to formation of a non-covalent complex that influences the activity of the target protein (66). Indeed, we observed physical interactions between hTRX variants and PAD4 in in vitro studies (Figures 5A,B) as well as in DMSO-differentiated HL60 cells (Figure 5C). Furthermore, interactions between C32/35/69ShTRX and PAD4 confirmed our prior inference from kinetic data that activity-enhancing interactions between hTRX and PAD4 occur at sites unaffected by mutation or chemical modification. In spite of several evidences that hTRX-mediated PAD activation does not require classical redox activity, DTT-treated hTRX showed enhanced activation of PAD4 compared to untreated hTRX. Such a difference can be attributed to change in binding of hTRX with PAD4 due to subtle conformational changes between reduced and oxidized forms of hTRX (Figure 6) (67, 68). In fact, the crystal structure of fully oxidized hTRX shows unraveling of a helix to form an extended loop (Figure 6, green). Since the binding affinity of oxidized and reduced hTRX was similar, one can only assume that the structural changes accompanying oxidation of hTRX makes the rate enhancing interactions less productive.

Generally, it is believed that PAD4-interacting proteins might promote its activity by lowering the $\mathrm{Ca}^{2+}$-dependence but this is not the case with hTRX (Figure 3B). Instead, non-covalently attached reduced hTRX likely provides localized high reduction potential near the active site that would prevent oxidation of the catalytic cysteine and facilitate the PAD4 catalysis. One such scenario could arise when hTRX and PAD share a substrate, for example, the transcription factor NF- $\kappa \mathrm{B}$. TRX is involved in the redox regulation of NF- $\kappa \mathrm{B}$, which is a known PAD substrate. In separate studies, Yosshida et al. showed that TRX accelerates the nuclear translocation of NF-kB (41) and Son et al. showed that citrullination of NF- $\mathrm{B}$ enhances its nuclear localization (69). The present study provides a link between these processes and suggests that it could be hTRX mediated PAD4 catalyzed citrullination that enhances the nuclear localization of NF-кB. 
Based on our findings and the existing literature, we propose the following model to explain how environmental factors could trigger dysregulated PAD activity (Figure 7). Environmental factors that induce oxidative stress, such as smoking, pollution, and infections leads to higher expression of hTRX to combat increasing reactive oxygen species $(59,70,71)$. Apart from hTRX, oxidative stress increases intracellular concentration of $\mathrm{Ca}^{2+}$ by promoting the influx of $\mathrm{Ca}^{2+}$ from the extracellular matrix and by releasing $\mathrm{Ca}^{2+}$ from reserves in the ER $(72,73)$. Thus, oxidative stress provides perfect conditions, i.e., elevated levels of hTRX and $\mathrm{Ca}^{2+}$, to trigger PAD activity in the cytosol as well as in the nucleus. In fact, $\mathrm{H}_{2} \mathrm{O}_{2}$ treated primary murine and human neutrophils showed enhanced PAD4-mediated histone citrullination $(74,75)$. Such aberrant PAD activity in the nucleus can cause NETosis, an event that would release active PADs into the extracellular matrix leading to uncontrolled citrullination and its pathogenic repercussions (Figure 7) (5-7). In summary, our data show that hTRX regulates PAD4 activity through a noncanonical mechanism that does not require its reducing activity; instead, non-covalent interactions are sufficient for thioredoxin mediated PAD activation.

\section{REFERENCES}

1. Fuhrmann J, Thompson PR. Protein arginine methylation and citrullination in epigenetic regulation. ACS Chem Biol. (2016) 11:654-68. doi: 10.1021/acschembio.5b00942

2. Witalison EE, Thompson PR, Hofseth LJ. Protein arginine deiminases and associated citrullination: physiological functions and diseases associated with dysregulation. Curr Drug Targets (2015) 16:700-10. doi: 10.2174/1389450116666150202160954

3. Tilvawala R, Nguyen SH, Maurais AJ, Nemmara VV, Nagar M, Salinger AJ, et al. The rheumatoid arthritis-associated citrullinome. Cell Chem Biol. (2018). 25:691-704.e6. doi: 10.1016/j.chembiol.2018.03.002

4. Baka Z, Gyorgy B, Geher P, Buzas EI, Falus A, Nagy G. Citrullination under physiological and pathological conditions. Joint Bone Spine (2012) 79:431-6. doi: $10.1016 /$ j.jbspin.2012.01.008

5. Rohrbach AS, Slade DJ, Thompson PR, Mowen KA. Activation of PAD4 in NET formation. Front Immunol. (2012) 3:360. doi: 10.3389/fimmu.2012.00360

6. Kaplan MJ, Radic M. Neutrophil extracellular traps: double-edged swords of innate immunity. J Immunol. (2012) 189:2689-95. doi: 10.4049/jimmunol.1201719

7. Wang Y, Li M, Stadler S, Correll S, Li P, Wang D, et al. Histone hypercitrullination mediates chromatin decondensation and neutrophil extracellular trap formation. J Cell Biol. (2009) 184:205-13. doi: $10.1083 /$ jcb.200806072

8. van Venrooij WJ, Pruijn GJ. How citrullination invaded rheumatoid arthritis research. Arthritis Res Ther. (2014) 16:103. doi: 10.1186/ar4458

9. Wegner N, Lundberg K, Kinloch A, Fisher B, Malmstrom V, Feldmann M, et al. Autoimmunity to specific citrullinated proteins gives the first clues to the etiology of rheumatoid arthritis. Immunol Rev. (2010) 233:34-54. doi: 10.1111/j.0105-2896.2009.00850.x

10. Vander Cruyssen B, Peene I, Cantaert T, Hoffman IE, De Rycke L, Veys EM, et al. Anti-citrullinated protein/peptide antibodies (ACPA) in rheumatoid arthritis: specificity and relation with rheumatoid factor. Autoimmun Rev. (2005) 4:468-74. doi: 10.1016/j.autrev.2005.04.018

11. Chandra PE, Sokolove J, Hipp BG, Lindstrom TM, Elder JT, Reveille JD, et al. Novel multiplex technology for diagnostic characterization of rheumatoid arthritis. Arthritis Res Ther. (2011) 13:R102. doi: 10.1186/ar3383

12. Aggarwal R, Liao K, Nair R, Ringold S, Costenbader KH. Anticitrullinated peptide antibody assays and their role in the diagnosis of

\section{AUTHOR CONTRIBUTIONS}

$\mathrm{MN}$ and PT designed the study and analyzed data, and wrote the manuscript. MN performed the experiments. RT optimized PAD4 expression in HL60 cells.

\section{FUNDING}

This study was funded by grants to PT from the NIH (R35GM118112).

\section{ACKNOWLEDGMENTS}

We thank Dr. Eranthie Weerapana (Associate Professor, Boston College, MA) for providing hTRX plasmids.

\section{SUPPLEMENTARY MATERIAL}

The Supplementary Material for this article can be found online at: https://www.frontiersin.org/articles/10.3389/fimmu. 2019.00244/full\#supplementary-material

rheumatoid arthritis. Arthritis Rheum. (2009) 61:1472-83. doi: 10.1002/art. 24827

13. Knight JS, Subramanian V, O'Dell AA, Yalavarthi S, Zhao W, Smith CK, et al. Peptidylarginine deiminase inhibition disrupts NET formation and protects against kidney, skin and vascular disease in lupus-prone MRL/lpr mice. Ann Rheum Dis. (2015) 74:2199-206. doi: 10.1136/annrheumdis-2014205365

14. Chumanevich AA, Causey CP, Knuckley BA, Jones JE, Poudyal D, Chumanevich AP, et al. Suppression of colitis in mice by Cl-amidine: a novel peptidylarginine deiminase inhibitor. Am J Physiol Gastrointest Liver Physiol. (2011) 300:G929-38. doi: 10.1152/ajpgi.00435.2010

15. Moscarello MA, Mastronardi FG, Wood DD. The role of citrullinated proteins suggests a novel mechanism in the pathogenesis of multiple sclerosis. Neurochem Res. (2007) 32:251-6. doi: 10.1007/s11064-006-9144-5

16. Rondas D, Crevecoeur I, D’Hertog W, Ferreira GB, Staes A, Garg AD, et al. Citrullinated glucose-regulated protein 78 is an autoantigen in type 1 diabetes. Diabetes (2015) 64:573-86. doi: 10.2337/db14-0621

17. Mohanan S, Cherrington BD, Horibata S, McElwee JL, Thompson PR, Coonrod SA. Potential role of peptidylarginine deiminase enzymes and protein citrullination in cancer pathogenesis. Biochem Res Int. (2012) 2012:895343. doi: $10.1155 / 2012 / 895343$

18. Nicholas AP. Dual immunofluorescence study of citrullinated proteins in Parkinson diseased substantia nigra. Neurosci Lett. (2011) 495:26-9. doi: 10.1016/j.neulet.2011.03.028

19. Ishigami A, Ohsawa T, Hiratsuka M, Taguchi H, Kobayashi S, Saito $\mathrm{Y}$, et al. Abnormal accumulation of citrullinated proteins catalyzed by peptidylarginine deiminase in hippocampal extracts from patients with Alzheimer's disease. J Neurosci Res. (2005) 80:120-8. doi: 10.1002/jnr.20431

20. Mondal S, Parelkar SS, Nagar M, Thompson PR. Photochemical control of Protein Arginine Deiminase (PAD) activity. ACS Chem Biol. (2018) 13:105765. doi: 10.1021/acschembio.8b00053

21. Ledet MM, Anderson R, Harman R, Muth A, Thompson PR, Coonrod SA, et al. BB-Cl-Amidine as a novel therapeutic for canine and feline mammary cancer via activation of the endoplasmic reticulum stress pathway. BMC Cancer (2018) 18:412. doi: 10.1186/s12885-018-4323-8

22. Muth A, Subramanian V, Beaumont E, Nagar M, Kerry P, McEwan P, et al. Development of a selective inhibitor of protein arginine deiminase 2. J Med Chem. (2017) 60:3198-211. doi: 10.1021/acs.jmedchem.7b00274

23. Kosgodage US, Trindade RP, Thompson PR, Inal JM, Lange S. Chloramidine/Bisindolylmaleimide-I-mediated inhibition of exosome 
and microvesicle release and enhanced efficacy of cancer chemotherapy. Int $J$ Mol Sci. (2017) 18:E1007. doi: 10.3390/ijms 18051007

24. Luo Y, Knuckley B, Lee YH, Stallcup MR, Thompson PR. A fluoroacetamidine-based inactivator of protein arginine deiminase 4: design, synthesis, and in vitro and in vivo evaluation. J Am Chem Soc. (2006) 128:1092-3. doi: 10.1021/ja0576233

25. Clancy KW, Russell AM, Subramanian V, Nguyen H, Qian Y, Campbell $\mathrm{RM}$, et al. Citrullination/methylation crosstalk on histone $\mathrm{H} 3$ regulates ER-target gene transcription. ACS Chem Biol. (2017) 12:1691-702. doi: 10.1021/acschembio.7b00241

26. Vossenaar ER, Zendman AJ, van Venrooij WJ, Pruijn GJ. PAD, a growing family of citrullinating enzymes: genes, features and involvement in disease. Bioessays (2003) 25:1106-18. doi: 10.1002/bies.10357

27. Senshu T, Kan S, Ogawa H, Manabe M, Asaga H. Preferential deimination of keratin $\mathrm{K} 1$ and filaggrin during the terminal differentiation of human epidermis. Biochem Biophys Res Commun. (1996) 225:712-9. doi: 10.1006/bbrc.1996.1240

28. Zhou Y, Chen B, Mittereder N, Chaerkady R, Strain M, An LL, et al. Spontaneous secretion of the citrullination enzyme PAD2 and cell surface exposure of PAD4 by neutrophils. Front Immunol. (2017) 8:1200. doi: 10.3389/fimmu.2017.01200

29. Vossenaar ER, Radstake TR, van der Heijden A, van Mansum MA, Dieteren C, de Rooij DJ, et al. Expression and activity of citrullinating peptidylarginine deiminase enzymes in monocytes and macrophages. Ann Rheum Dis. (2004) 63:373-81. doi: 10.1136/ard.2003.012211

30. Slade DJ, Fang P, Dreyton CJ, Zhang Y, Fuhrmann J, Rempel D, et al. Protein arginine deiminase 2 binds calcium in an ordered fashion: implications for inhibitor design. ACS Chem Biol. (2015) 10:1043-53. doi: 10.1021/cb500933j

31. Knuckley B, Causey CP, Jones JE, Bhatia M, Dreyton CJ, Osborne TC, et al. Substrate specificity and kinetic studies of PADs 1, 3, and 4 identify potent and selective inhibitors of protein arginine deiminase 3. Biochemistry (2010) 49:4852-63. doi: 10.1021/bi100363t

32. Knuckley B, Bhatia M, Thompson PR. Protein arginine deiminase 4: evidence for a reverse protonation mechanism. Biochemistry (2007) 46:6578-87. doi: 10.1021/bi700095s

33. Zhou Y, Mittereder N, Sims GP. Perspective on protein arginine deiminase activity-bicarbonate is a $\mathrm{pH}$-independent regulator of citrullination. Front Immunol. (2018) 9:34. doi: 10.3389/fimmu.2018.00034

34. Damgaard D, Bjorn ME, Steffensen MA, Pruijn GJ, Nielsen CH. Reduced glutathione as a physiological co-activator in the activation of peptidylarginine deiminase. Arthritis Res Ther. (2016) 18:102. doi: 10.1186/s13075-0161000-7

35. Palde PB, Carroll KS. A universal entropy-driven mechanism for thioredoxin-target recognition. Proc Natl Acad Sci USA. (2015) 112:7960-5. doi: 10.1073/pnas. 1504376112

36. Lu J, Holmgren A. The thioredoxin antioxidant system. Free Radic Biol Med. (2014) 66:75-87. doi: 10.1016/j.freeradbiomed.2013.07.036

37. Hall G, Emsley J. Structure of human thioredoxin exhibits a large conformational change. Protein Sci. (2010) 19:1807-11. doi: 10.1002/pro.466

38. Lu T, Zong M, Fan S, Lu Y, Yu S, Fan L. Thioredoxin 1 is associated with the proliferation and apoptosis of rheumatoid arthritis fibroblast-like synoviocytes. Clin Rheumatol. (2018) 37:117-25. doi: 10.1007/s10067-017-3832-1

39. Xie Z, Sun J, Li H, Shao T, Wang D, Zheng Q, et al. Plasma and synovial fluid TrxR levels are correlated with disease risk and severity in patients with rheumatoid arthritis. Medicine (2016) 95:e2543. doi: 10.1097/MD.0000000000002543

40. Jikimoto T, Nishikubo Y, Koshiba M, Kanagawa S, Morinobu S, Morinobu A, et al. Thioredoxin as a biomarker for oxidative stress in patients with rheumatoid arthritis. Mol Immunol. (2002) 38:765-72. doi: 10.1016/S0161-5890(01)00113-4

41. Yoshida S, Katoh T, Tetsuka T, Uno K, Matsui N, Okamoto T. Involvement of thioredoxin in rheumatoid arthritis: its costimulatory roles in the TNFalpha-induced production of IL-6 and IL-8 from cultured synovial fibroblasts. J Immunol. (1999) 163:351-8.

42. Maurice MM, Nakamura H, van der Voort EA, van Vliet AI, Staal FJ, Tak PP, et al. Evidence for the role of an altered redox state in hyporesponsiveness of synovial T cells in rheumatoid arthritis. J Immunol. (1997) 158:1458-65.
43. King BC, Nowakowska J, Karsten CM, Kohl J, Renstrom E, Blom AM. Truncated and full-length thioredoxin-1 have opposing activating and inhibitory properties for human complement with relevance to endothelial surfaces. J Immunol. (2012) 188:4103-12. doi: 10.4049/jimmunol.1101295

44. Lundstrom J, Holmgren A. Determination of the reduction-oxidation potential of the thioredoxin-like domains of protein disulfide-isomerase from the equilibrium with glutathione and thioredoxin. Biochemistry (1993) 32:6649-55. doi: 10.1021/bi00077a018

45. Kearney PL, Bhatia M, Jones NG, Yuan L, Glascock MC, Catchings KL, et al. Kinetic characterization of protein arginine deiminase 4: a transcriptional corepressor implicated in the onset and progression of rheumatoid arthritis. Biochemistry (2005) 44:10570-82. doi: 10.1021/bi050292m

46. Lewallen DM, Bicker KL, Subramanian V, Clancy KW, Slade DJ, Martell J, et al. Chemical proteomic platform to identify citrullinated proteins. ACS Chem Biol. (2015) 10:2520-8. doi: 10.1021/acschembio.5b00438

47. Ghari F, Quirke AM, Munro S, Kawalkowska J, Picaud S, McGouran $\mathrm{J}$, et al. Citrullination-acetylation interplay guides E2F-1 activity during the inflammatory response. Sci Adv. (2016) 2:e1501257. doi: 10.1126/sciadv.1501257

48. Guo Q, Wang Y, Xu D, Nossent J, Pavlos NJ, Xu J. Rheumatoid arthritis: pathological mechanisms and modern pharmacologic therapies. Bone Res. (2018) 6:15. doi: 10.1038/s41413-018-0016-9

49. Malmstrom V, Catrina AI, Klareskog L. The immunopathogenesis of seropositive rheumatoid arthritis: from triggering to targeting. Nat Rev Immunol. (2017) 17:60-75. doi: 10.1038/nri.2016.124

50. Raychaudhuri S, Sandor C, Stahl EA, Freudenberg J, Lee HS, Jia X, et al. Five amino acids in three HLA proteins explain most of the association between MHC and seropositive rheumatoid arthritis. Nat Genet. (2012) 44:291-6. doi: 10.1038/ng.1076

51. Smallwood MJ, Nissim A, Knight AR, Whiteman M, Haigh R, Winyard PG. Oxidative stress in autoimmune rheumatic diseases. Free Radic Biol Med. (2018) 125:3-14. doi: 10.1016/j.freeradbiomed.2018.05.086

52. Hitchon CA, El-Gabalawy HS. Oxidation in rheumatoid arthritis. Arthritis Res Ther. (2004) 6:265-78. doi: 10.1186/ar1447

53. Garcia-Gonzalez A, Gaxiola-Robles R, Zenteno-Savin T. Oxidative stress in patients with rheumatoid arthritis. Rev Invest Clin. (2015) 67:46-53.

54. Veselinovic M, Barudzic N, Vuletic M, Zivkovic V, Tomic-Lucic A, Djuric D, et al. Oxidative stress in rheumatoid arthritis patients: relationship to diseases activity. Mol Cell Biochem. (2014) 391:225-32. doi: 10.1007/s11010-014-2006-6

55. Franco R, Panayiotidis MI, Cidlowski JA. Glutathione depletion is necessary for apoptosis in lymphoid cells independent of reactive oxygen species formation. J Biol Chem. (2007) 282:30452-65. doi: 10.1074/jbc.M703091200

56. Mytilineou C, Kramer BC, Yabut JA. Glutathione depletion and oxidative stress. Parkinsonism Relat Disord. (2002) 8:385-7. doi: 10.1016/S1353-8020(02)00018-4

57. Hassan MQ, Hadi RA, Al-Rawi ZS, Padron VA, Stohs SJ. The glutathione defense system in the pathogenesis of rheumatoid arthritis. J Appl Toxicol. (2001) 21:69-73. doi: 10.1002/jat.736

58. Aukrust P, Svardal AM, Muller F, Lunden B, Berge RK, Froland SS. Decreased levels of total and reduced glutathione in CD4+ lymphocytes in common variable immunodeficiency are associated with activation of the tumor necrosis factor system: possible immunopathogenic role of oxidative stress. Blood (1995) 86:1383-91.

59. Mougiakakos D, Johansson CC, Jitschin R, Bottcher M, Kiessling R. Increased thioredoxin-1 production in human naturally occurring regulatory $\mathrm{T}$ cells confers enhanced tolerance to oxidative stress. Blood (2011) 117:857-61. doi: 10.1182/blood-2010-09-307041

60. Bertini R, Howard OM, Dong HF, Oppenheim JJ, Bizzarri C, Sergi R, et al. Thioredoxin, a redox enzyme released in infection and inflammation, is a unique chemoattractant for neutrophils, monocytes, and T cells. J Exp Med. (1999) 189:1783-9. doi: 10.1084/jem.189.11.1783

61. Cheng Z, Zhang J, Ballou DP, Williams CH, Jr. Reactivity of thioredoxin as a protein thiol-disulfide oxidoreductase. Chem Rev. (2011) 111:5768-83. doi: $10.1021 / \operatorname{cr} 100006 \mathrm{x}$

62. Haberlein I, Wurfel M, Follmann H. Non-redox protein interactions in the thioredoxin activation of chloroplast enzymes. Biochim Biophys Acta (1992) 1121:293-6. doi: 10.1016/0167-4838(92)90159-B 
63. Watson WH, Pohl J, Montfort WR, Stuchlik O, Reed MS, Powis G, et al. Redox potential of human thioredoxin 1 and identification of a second dithiol/disulfide motif. J Biol Chem. (2003) 278:33408-15. doi: 10.1074/jbc.M211107200

64. Liu Y, Min W. Thioredoxin promotes ASK1 ubiquitination and degradation to inhibit ASK1-mediated apoptosis in a redox activity-independent manner. Circ Res. (2002) 90:1259-66. doi: 10.1161/01.RES.0000022160. 64355.62

65. Huber HE, Russel M, Model P, Richardson CC. Interaction of mutant thioredoxins of Escherichia coli with the gene 5 protein of phage T7. The redox capacity of thioredoxin is not required for stimulation of DNA polymerase activity. J Biol Chem. (1986) 261:15006-12.

66. Mora-Garcia S, Rodriguez-Suarez R, Wolosiuk RA. Role of electrostatic interactions on the affinity of thioredoxin for target proteins. Recognition of chloroplast fructose-1, 6-bisphosphatase by mutant Escherichia coli thioredoxins. J Biol Chem. (1998) 273:16273-80. doi: $10.1074 /$ jbc.273.26.16273

67. Hwang J, Nguyen LT, Jeon YH, Lee CY, Kim MH. Crystal structure of fully oxidized human thioredoxin. Biochem Biophys Res Commun. (2015) 467:218-22. doi: 10.1016/j.bbrc.2015.10.003

68. Weichsel A, Gasdaska JR, Powis G, Montfort WR. Crystal structures of reduced, oxidized, and mutated human thioredoxins: evidence for a regulatory homodimer. Structure (1996) 4:735-51. doi: 10.1016/S0969-2126(96)00079-2

69. Sun B, Dwivedi N, Bechtel TJ, Paulsen JL, Muth A, Bawadekar M, et al. Citrullination of NF- $\kappa \mathrm{B}$ p65 promotes its nuclear localization and TLRinduced expression of IL-1 $\beta$ and TNF $\alpha$. Sci Immunol. (2017) 2:eaal3062. doi: 10.1126/sciimmunol.aal3062

70. Yodoi J, Matsuo Y, Tian H, Masutani H, Inamoto T. Anti-inflammatory thioredoxin family proteins for medicare, healthcare and aging care. Nutrients (2017) 9:E1081. doi: 10.3390/nu9101081
71. Mimura K, Kua LF, Shimasaki N, Shiraishi K, Nakajima S, Siang LK, et al. Upregulation of thioredoxin-1 in activated human NK cells confers increased tolerance to oxidative stress. Cancer Immunol Immunother. (2017) 66:605-13. doi: 10.1007/s00262-017-1969-z

72. Hempel N, Trebak M. Crosstalk between calcium and reactive oxygen species signaling in cancer. Cell Calcium (2017) 63:70-96. doi: 10.1016/j.ceca.2017.01.007

73. Gorlach A, Bertram K, Hudecova S, Krizanova O. Calcium and ROS: a mutual interplay. Redox Biol. (2015) 6:260-71. doi: 10.1016/j.redox.2015.08.010

74. Li P, Li M, Lindberg MR, Kennett MJ, Xiong N, Wang Y. PAD4 is essential for antibacterial innate immunity mediated by neutrophil extracellular traps. J Exp Med. (2010) 207:1853-62. doi: 10.1084/jem.20100239

75. Neeli I, Khan SN, Radic M. Histone deimination as a response to inflammatory stimuli in neutrophils. J Immunol. (2008) 180:1895-902. doi: 10.4049/jimmunol.180.3.1895

Conflict of Interest Statement: PT was a founder of Padlock Therapeutics which was acquired by Bristol Myers Squibb in 2016 and is entitled to payments if certain milestones are met. PT is a consultant for Celgene and Disarm Therapeutics.

The remaining authors declare that the research was conducted in the absence of any commercial or financial relationships that could be construed as a potential conflict of interest.

Copyright (C) 2019 Nagar, Tilvawala and Thompson. This is an open-access article distributed under the terms of the Creative Commons Attribution License (CC BY). The use, distribution or reproduction in other forums is permitted, provided the original author(s) and the copyright owner(s) are credited and that the original publication in this journal is cited, in accordance with accepted academic practice. No use, distribution or reproduction is permitted which does not comply with these terms. 